\title{
Women develop diabetes at higher BMIs than men
}

\author{
H. Sourij • R. R. Holman
}

Received: 11 November 2011 / Accepted: 2 December 2011 /Published online: 6 January 2012

(C) Springer-Verlag 2012

Keywords BMI · Diabetes mellitus · Sex differences

To the Editor: In their analysis of the British Regional Heart Study and the British Women's Heart Health Study, Wannamethee and colleagues report that women develop diabetes at higher BMIs than men [1]. This is a wellrecognised finding. In 1988 the UK Prospective Diabetes Study (UKPDS) demonstrated, in 1,857 Caucasian, AfroCaribbean and Asian patients, that men with newly diagnosed type 2 diabetes were significantly less obese than their female counterparts, being $120.8 \pm 19.7 \%$ vs $140.9 \pm 29.1 \%$ (mean $\pm \mathrm{SD}$ ) of ideal body weight, respectively [2]. This result was subsequently confirmed by a study using a US database, which also showed that BMI was higher for women with newly diagnosed diabetes than for men, although this difference declined with age [3].

More recently, a prospective analysis of the Monitoring Trends and Determinants in Cardiovascular Diseases (MONICA) Augsburg cohort study showed that the diabetes incidence rate per 10,000 person-years was substantially higher in men below the lowest BMI quartile $\left(<25.1 \mathrm{~kg} / \mathrm{m}^{2}\right)$ than women $\left(<23.4 \mathrm{~kg} / \mathrm{m}^{2}\right)$, being 31.3 and 5.5 , respectively

H. Sourij · R. R. Holman $(\bowtie)$

Diabetes Trials Unit, Oxford Centre for Diabetes,

Endocrinology and Metabolism, Churchill Hospital,

Oxford OX3 7LJ, UK

e-mail: rury.holman@dtu.ox.ac.uk

H. Sourij

Division of Endocrinology and Metabolism,

Medical University of Graz,

Graz, Austria
[4]. However, the multivariate adjusted hazard ratio for incident type 2 diabetes for those above the highest quartile, compared with those below the lowest quartile, was greater in women (10.6) than in men (4.2), suggesting a much steeper rise in diabetes incidence with increasing BMI in women. This finding was noted in 1985 by Bonham and Brock in their analysis of the National Health Interview Survey, which stated that '...the prevalence of reported diabetes increased more rapidly with increased body mass among women than men' [5].

We agree with Wannamethee and colleagues that the higher degree of adiposity seen in women than men with new-onset diabetes may explain in part the higher risk for cardiovascular disease observed in women with diabetes relative to men with diabetes, compared with their non-diabetic counterparts.

Acknowledgements R.R. Holman is an NIHR Senior Investigator.

Contribution statement Both authors were responsible for the conception and design of the manuscript, drafting the article and revising it critically for important intellectual content. Both authors approved the final version to be published.

Duality of interest The authors declare that there is no duality of interest associated with this manuscript.

\section{References}

1. Wannamethee SG, Papacosta O, Lawlor DA et al (2011) Do women exhibit greater differences in established and novel risk factors between diabetes and non-diabetes than men? The British Regional Heart Study and British Women's Heart Health Study. Diabetologia $55: 80-87$ 
2. United Kingdom Prospective Diabetes Study Group (1988) UK Prospective Diabetes Study. IV. Characteristics of newly presenting type 2 diabetic patients: male preponderance and obesity at different ages. Diabet Med 5:154-159

3. Leibson CL, Williamson DF, Melton LJ 3rd et al (2001) Temporal trends in BMI among adults with diabetes. Diabetes Care 24:1584-1589
4. Meisinger C, Doring A, Thorand B, Heier M, Lowel H (2006) Body fat distribution and risk of type 2 diabetes in the general population: are there differences between men and women? The MONICA/KORA Augsburg cohort study. Am J Clin Nutr 84:483-489

5. Bonham GS, Brock DB (1985) The relationship of diabetes with race, sex, and obesity. Am J Clin Nutr 41:776-783 